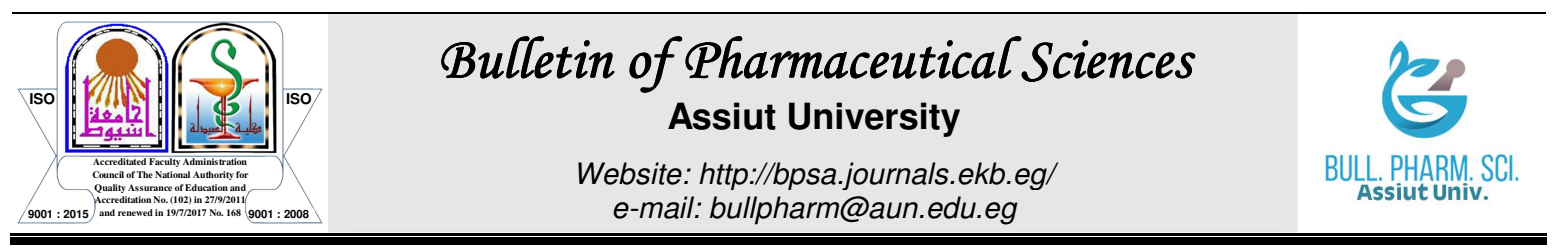

\title{
OPTIMIZATION OF CULTURE CONDITIONS FOR KOJIC ACID PRODUCTION IN SURFACE FERMENTATION BY ASPERGILLUS ORYZAE ISOLATED FROM WHEAT GRAINS
}

\author{
Abdel-Hamied M. Rasmey ${ }^{1 *}$ and Marwa Abdel-Kareem ${ }^{2}$ \\ ${ }^{1}$ Department of Botany \& Microbiology, Faculty of Science, Suez University, Suez 43518, \\ Egypt \\ ${ }^{2}$ Department of Botany \& Microbiology, Faculty of Science, Sohag University, Sohag 82524, \\ Egypt
}

\begin{abstract}
Kojic acid is a natural organic acid synthesized during aerobic fermentation of carbohydrates as a secondary metabolite by some species of Aspergillus and has been used commercially in several industrial applications. The current investigation aims to optimize the culture conditions for kojic acid production from starch as a carbon source by the novel isolate Aspergillus oryzae 1034. Seventy-five isolates representing 11 species of Aspergillus were isolated from stored wheat grains and screened for kojic acid biosynthesis. Amongst, A. oryzae 1034 was selected as the most potent kojic acid producer from starch. This strain was subjected to different fermentation conditions to maximize the kojic acid production from starch versus glucose. The results concluded that glucose and starch substrates in concentrations 60 and 80 $\mathrm{g} / \mathrm{l}$, respectively were the optima for kojic acid production. The optimum phosphorus concentration was 0.5 and $2.0 \mathrm{~g} / \mathrm{KH}_{2} \mathrm{PO}_{4}$ in glucose and starch media, respectively. The maximum kojic acid yield was attained at $28^{\circ} \mathrm{C}$ for 11 days of incubation in both glucose and starch media with $\mathrm{pH} 4.5$ and 5.0, respectively. Supplementation of $\mathrm{Pb}^{+2}$ to glucose medium and $\mathrm{Zn}^{+2}$ to starch medium stimulated the biosynthesis of kojic acid to 79.3 and $68.8 \mathrm{~g} / \mathrm{l}$, respectively. Alternatively, kojic acid biosynthesis was decreased by supplementation of amino acids in the fermentation medium. These findings suggest the possibility of using A. oryzae 1034 as a promising.
\end{abstract}

\section{INTRODUCTION}

Kojic acid (5-hydroxy-2-hydroxymethyl- $\gamma$ pyrone) is a natural organic acid was initially extracted from fermented steamed rice (known as "koji" in Japanese) in Japan by Saito in $1907^{1}$. Kojic acid is a secondary metabolite formed during aerobic fermentation of carbohydrates by several species of fungi as well as some bacterial strains of the two bacterial genera Acetobacter and Brevibacterium $^{2-4}$. Aspergillus and Penicillium species are widely known among fungi as the best kojic acid producers ${ }^{5}$. Amongst the species of Aspergillus, A. flavus $^{6}$, A. oryzae ${ }^{7}, A$. tamarii $^{8}$ and $A$. parasiticus $^{9}$ were regarded as the main kojic acid source in large amounts.

Nowadays, kojic acid has numerous industrial and biotechnological applications in food processing, chemicals, cosmetics and pharmaceuticals preparation ${ }^{10}$. For instance, kojic acid is now extensively used in cosmetic industries as a metal chelating agent due to its tyrosinase inhibition ability, thus it is used as a lotion for skin whitening and protection against the sunlight ${ }^{11}$. In the medicine, it is used as a pain killer, antibacterial against Gram-negative bacteria and anti-inflammatory drug ${ }^{3 \& 12}$. In the food processing, it is used as a precursor of flavors and as a preserving material in agricultural products during storage, especially

Received in 2/2/2021 \& Accepted in 24/3/2021 
vegetables and fruits by inhibiting the polyphenol oxidase (PPO) action ${ }^{13}$. Kojic acid is documented in different studies as a precursor or an intermediate compound in chemicals production that can be used as therapeutic agents ${ }^{3}$. At the carbon 5 of pyrone ring, the hydroxyl group acts as a weak acid, make it is able to form salts with some metals like sodium, zinc, calcium, and cadmium ${ }^{14}$.

Kojic acid has melting point ranges from $151-154^{\circ} \mathrm{C}$ and it crystallizes as colourless prismatic needles in water under cooling centrifugation ${ }^{11}$. It is characterized by its high solubility in water, ethanol and ethyl acetate while less soluble in ether and chloroform ${ }^{15}$.

The apparently similar structure between the pyranose ring of glucose and the pyrone ring of kojic acid had paid the attention of researchers towards studying the pathways of its biosynthesis from glucose and other substrates. Some enzymes like glucose dehydrogenase, glucosen - 6-phosphate dehydrogenase, 6- phosphogluconate dehydrogenase, glucose oxidase and gluconate dehydrogenase have been detected in mycelial extracts of different isolates of Aspergillus flavus that gives kojic acid in large amounts. Also, kojic acid was detected with pentoses, glycerol, starch and dihydroxyacetone as substrates 5 .

Though kojic acid has been produced industrially and applied in different applications, its production is still an interesting research area. The main subjects must be considered for enhancement of kojic acid biosynthesis are the strain development and the development of fermentation process. This could be attained either by manipulation of the microbial strains or optimization of the culture conditions ${ }^{16 \& 17}$. Thus, the current research is aimed to investigate the ability of some Aspergillus species isolated from wheat grains to produce kojic acid in batch culture. Subsequently, the optimization of cultural conditions for kojic acid production from glucose and starch by the highly producer isolate was conducted.

\section{MATERIALS AND METHODS}

\section{Isolation of Aspergillus species}

Thirty samples of wheat grains stored under wet atmosphere were collected from different shops in Suez city, Egypt, for isolation of Aspergillus species. The isolation was performed by pour plate method onto Czapek's agar according to Christensen ${ }^{18}$. Modified Czapek's agar medium contained ( $\mathrm{g} / \mathrm{l}$ dist. $\mathrm{H}_{2} \mathrm{O}$ ): starch, 10.0; $\mathrm{NaNO}_{3}, 3.0 ; \mathrm{KH}_{2} \mathrm{PO}_{4}$, $1.0 ; \mathrm{MgSO}_{4}, 0.5 ; \mathrm{KCl}, 0.5$; and agar, 18.0. Chloroamphenicol $(50 \mu \mathrm{g} / \mathrm{ml})$ and rose bengal $(10 \mu \mathrm{g} / \mathrm{ml})$ were added to inhibit the growth of bacteria. The prepared medium was adjusted to pH 6.5 using $\mathrm{HCl} 0.1 \mathrm{~N}$ and $\mathrm{NaOH} 0.1 \mathrm{~N}$. This medium was autoclaved at $121^{\circ} \mathrm{C}$ for 15 minutes. The inoculated plates were incubated at $28^{\circ} \mathrm{C}$ for 7 days. The growing Aspergillus colonies were picked up, transferred to agar slants and stored at $4^{\circ} \mathrm{C}$. The results for each species in the sample were recorded as colony forming units (CFU).

\section{Identification of Aspergillus species}

The isolated Aspergillus species were characterized and identified to the genus and species level according to Moubasher ${ }^{19}$, based on the studied microscopic and macroscopic morphological characters of their colonies and mycelia.

\section{Preparation of spore suspension}

The spore suspension was prepared by growing the fungus on potato dextrose agar (PDA) for 5 days and their spores were collected using $1 \%(\mathrm{v} / \mathrm{v})$ of tween solution. The spore suspension concentration was adjusted to be $5 \times 10^{6}$ spores per one $\mathrm{ml}$.

\section{Fermentation process for kojic acid production}

The used fermentation medium for production of kojic acid consists $(\mathrm{g} / \mathrm{L})$ : soluble starch, 50; yeast extract, 5.0; $\mathrm{KH}_{2} \mathrm{PO}_{4}, 1.5$ and $\mathrm{MgSO}_{4}, 0.5$. This medium was adjusted to $\mathrm{pH}$ 3.5 using $\mathrm{HCl} 0.1 \mathrm{~N}$. Each $50 \mathrm{ml}$ medium were sterilized at $121^{\circ} \mathrm{C}$ for $15 \mathrm{~min}$ and inoculated with one $\mathrm{ml}$ spores suspension $\left(5 \times 10^{6}\right.$ $\mathrm{CFU} / \mathrm{ml})$. The cultures were incubated at $28 \pm 2^{\circ} \mathrm{C}$ for 8 days as a static cultivation ${ }^{3}$.

\section{Assay of kojic acid}

The formed kojic acid was determined in culture supernatant by a colorimetric method using ferric chloride $\left(\mathrm{FeCl}_{3}\right)$ reagent according to $B_{e n t l e y}{ }^{20}$. The reagent was prepared by dissolving one gram of $\mathrm{FeCl}_{3} \cdot 6 \mathrm{H}_{2} \mathrm{O}$ in $100 \mathrm{ml}$ 
of $0.1 \mathrm{~N} \mathrm{HCl}$. The reaction between the functional group of hydroxyl and pyrone rings in the samples gives a deep red colour with the reagent. The absorbance of the mixture was measured at $500 \mathrm{~nm}$ using spectrophotometer. The kojic acid equivalent was determined from kojic acid standard curve.

\section{Kojic acid fermentation from glucose and starch as carbon sources}

Glucose and starch were individually supplemented to the basal fermentation medium in amount equivalent to $50 \mathrm{~g} / 1$ of carbon. The cultures were incubated at $28 \pm 2^{\circ} \mathrm{C}$ for 8 days.

Optimized culture conditions for kojic acid production from glucose and starch by $A$. oryzae 1034

The influences of different culture conditions included substrate concentration, phosphorus concentration, initial $\mathrm{pH}$ value, incubation temperature, incubation period, amino acids concentration and heavy metals concentration on kojic acid biosynthesis in the fermentation medium were investigated. Effect of different glucose and starch concentrations $(10-80 \mathrm{~g} / \mathrm{l})$ with $10 \mathrm{~g} / \mathrm{l}$ interval in the fermentation medium was studied. Also, the effect of phosphorus concentration in the form of $\mathrm{KH}_{2} \mathrm{PO}_{4}(0.5-3.0 \mathrm{~g} / \mathrm{l})$ with $0.5 \mathrm{~g} / \mathrm{l}$ interval was tested. To determine the optimum $\mathrm{pH}$ for kojic acid production, initial $\mathrm{pH}$ of the medium was adjusted to $2.5,3.0,4.0,4.5,5.0$ and 6.0. The culture was incubated at different temperatures $\left(5,20,28,37\right.$, and $\left.45^{\circ} \mathrm{C}\right)$ to determine the optimum incubation temperature. The incubation period was optimized by incubating the culture at different periods $(5,6$, $7,8,9,10,11,12,13,20)$. Effect of different amino acids (arginine, histidine, methionine, lysine and alanine) at $0.2 \mathrm{~g} / \mathrm{l}$ was determined. In addition, different heavy metals (manganese chloride, nickel chloride, zinc chloride, lead nitrate, copper hydroxide) at $0.003 \mathrm{~g} / \mathrm{l}$ were tested. At the end of each parameter, kojic acid was assayed.

\section{Statistical analysis}

The different experiments were achieved using one-way analysis of variance. The comparison of means was performed using
Duncan's multiple range test for the difference between means at $p<0.05$.

\section{RESULTS AND DISCUSSION}

Recently, the microbial source for production of significant commercial products was prevailed as an alternative way for the chemical methods, this is due to that microbial metabolites can be produced on large scale fermentation with low cost. Among these products, kojic acid could be produced in large amounts in simple fermentation process by different species of Aspergillus, particularly A. oryzae. The isolation and selection of new fungal strains from suitable substrates will help to increase the productivity. Also, the cost can be minimized by using suitable starting substrate. Therefore, this study has been performed to isolate a new strain of Aspergillus has the potentiality to produce kojic acid in large amount on starch in comparison with glucose as carbon sources in addition to optimize the culture conditions for production.

\section{Screening of kojic acid production by the isolated species of Aspergillus}

Eleven Aspergillus species were isolated and identified from 30 wheat grain samples collected from Suez city (Table 1). These species were A. aculateus, A. carneus, A. flavus, A. oryzae, A. fumigatus, A. niger, A. ochraceous, A. parasiticus, A. sydowii, A. terreus and A. ustus. A. flavus, A. fumigatus and $A$. niger were the highest occurrence three species followed by A. terreus with moderate occurrence while the rest species were recorded as rare occurrence. In a similar study ${ }^{3}$, they reported that six species of the genus Aspergillus were isolated from wheat grains and the most predominant species was $A$. flavus. These data are similar with Soliman ${ }^{21}$, who mentioned that the genus Aspergillus was the predominant in the collected wheat grains. Also, different recent studies were conducted on the associated fungi of stored grains and reported that Aspergillus was among the highest occurrence fungal genera on these grains $^{3 \& 21-25}$. The associated fungi on cereal grains might be come from different ways such as dust from air, soil, harvesting, transportation and storage ${ }^{26}$. 
Table 1: Isolation and screening of kojic acid production by Aspergillus species from 30 samples of stored wheat grains collected from Suez city.

\begin{tabular}{|c|c|c|c|c|c|c|c|}
\hline \multirow[b]{2}{*}{ Fungal species } & \multirow{2}{*}{$\begin{array}{c}\mathrm{CFU}^{*} / \mathrm{g} \\
\text { wheat } \\
\text { grains }\end{array}$} & \multirow[b]{2}{*}{ CFU\% } & \multirow{2}{*}{$\begin{array}{c}\text { NCI }^{* *} \\
\text { (out of } 30 \\
\text { samples) }\end{array}$} & \multirow[b]{2}{*}{$\mathrm{OR}^{* * *}$} & \multicolumn{3}{|c|}{ Kojic Acid (KA) detection } \\
\hline & & & & & $\begin{array}{c}\text { Tested } \\
\text { isolates }\end{array}$ & $\begin{array}{l}+\mathrm{ve} \\
\text { isolates }\end{array}$ & $\begin{array}{c}\text {-ve } \\
\text { isolates }\end{array}$ \\
\hline Aspergillus aculateus & 18 & 0.91 & 1 & $\mathrm{R}$ & 6 & 2 & 4 \\
\hline A. carneus & 2 & 0.10 & 1 & $\mathrm{R}$ & 2 & 0 & 2 \\
\hline A. flavus & 673.3 & 34.06 & 19 & $\mathrm{H}$ & 16 & 10 & 6 \\
\hline A. oryze & 8 & 0.40 & 2 & $\mathrm{R}$ & 8 & 8 & 0 \\
\hline A. fumigatus & 326 & 16.49 & 15 & $\mathrm{H}$ & 12 & 3 & 9 \\
\hline A. niger & 838 & 42.39 & 28 & $\mathrm{H}$ & 15 & 8 & 7 \\
\hline A. ochraceous & 2 & 0.10 & 1 & $\mathrm{R}$ & 3 & 1 & 2 \\
\hline A. parasiticus & 6 & 0.30 & 2 & $\mathrm{R}$ & 2 & 2 & 0 \\
\hline A. sydowii & 5.3 & 0.27 & 2 & $\mathrm{R}$ & 2 & 0 & 2 \\
\hline A. terreus & 92 & 4.65 & 11 & $\mathrm{M}$ & 7 & 5 & 2 \\
\hline A. ustus & 6 & 0.30 & 1 & $\mathrm{R}$ & 2 & 1 & 1 \\
\hline Total & 1976.666 & & & & 75 & 40 & 35 \\
\hline
\end{tabular}

$\mathrm{CFU}^{*}$ : Colony forming units, $\mathrm{NCI}^{* *}$ : Number of cases of isolation, $\mathrm{OR}^{* * *}$ : Occurrence remark, $\mathrm{R}$ : rare, $\mathrm{H}$ : high and M: moderate.

Seventy-five isolates of the obtained Aspergillus species were tested for their capacity to produce kojic acid in starch medium under aerobic conditions. The tested species with isolates of Aspergillus were A. aculateus (six), A. carneus (two), A. flavus (sixteen), A. oryzae (eight), A. fumigatus (twelve), A. niger (fifteen), A. ochraceous (three), A. parasiticus (two), A. sydowii (two), A. terreus (seven) and A. ustus (two). The isolates of A. carneus and A. sydowi were kojic acid non producers. Also, two isolates of both A. ochraceous and A. terreus besides one, four, six, nine and seven isolates of $A$. aculateus, $A$. flavus, A. fumigatus and A. niger were non producers of kojic acid. On the other hand, the all tested isolates of both $A$. oryzae and $A$. parasiticus were kojic acid producers. These species were also studied for kojic acid production in different previous investigations $\mathrm{s}^{3,9 \& 27-34}$. A. oryzae was reported as the most potential producer species of the genus Aspergillus for kojic acid production from various substrates ${ }^{3,9 \& 35}$. Thus, the eight isolates of $A$. oryzae were selected for quantitative detection of kojic acid production on starch as the sole carbon source in the fermentation medium as shown in table 2 . These isolates proved to produce high concentrations of kojic acid, of which $A$. oryzae 1034 produced the highest concentration and recorded $41.678 \pm 0.324 \mathrm{~g} / \mathrm{l}$. Aspergillus oryzae has been regarded in different studies as being of low pathogenicity, and no aflatoxins or any other carcinogenic metabolites producer; therefore, it is an excellent starter for the safe production of kojic acid. Rosfarizan and Ariff $^{33}$ recorded that Aspergillus species have the ability to produce amylase enzyme that hydrolyze starch into simple sugars for subsequent its conversion into kojic acid. The amount of produced kojic acid depend on the type of fermentable sugars available in the culture medium ${ }^{3}$.

Table 2: Kojic acid production from starch by the isolated Aspergillus oryzae.

\begin{tabular}{|l|c|}
\hline \multicolumn{1}{|c|}{ Isolate No. } & Kojic acid $(\mathrm{g} / \mathrm{l})$ \\
\hline A. oryzae 1008 & $32.7 \pm 0.003^{\mathrm{c}}$ \\
\hline A. oryzae 1021 & $37.3 \pm 0.239^{\mathrm{b}}$ \\
\hline A. oryzae 1034 & $41.7 \pm 0.324^{\mathrm{a}}$ \\
\hline A. oryzae 1052 & $33.7 \pm 0.033^{\mathrm{c}}$ \\
\hline A. oryzae 1054 & $28.1 \pm 0.001^{\mathrm{d}}$ \\
\hline A. oryzae 1071 & $38.9 \pm 0.026^{\mathrm{b}}$ \\
\hline A. oryzae 1074 & $36.8 \pm 0.350^{\mathrm{bc}}$ \\
\hline A. oryzae 1096 & $26.3 \pm 0.027^{\mathrm{d}}$ \\
\hline
\end{tabular}

Values are means of three replicates; values assigned the same letters are not significantly different $(p<0.005)$ in Tukey's test. 
For enhancing kojic acid production from starch versus glucose by the potential producer isolate A. oryzae 1034, the effects of some nutritional and environmental conditions were investigated.

\section{Optimization of culture conditions for kojic acid production \\ Effect of phosphorus concentration on kojic acid production}

The effect of phosphorus concentration in the medium on kojic acid biosynthesis from starch and glucose by A. oryzae 1034 was tested and the obtained data were presented in figure 1. It was noticed that kojic acid yield from starch was increased by increasing the phosphorus in the medium until reaching to 2.0 $\mathrm{g} / \mathrm{l}$ then declined after this concentration. In contrast, kojic acid production from glucose was decreased by gradual increasing of phosphorus concentration. The maximum kojic acid concentration in starch medium was $\mathbf{5 5 . 3 6}$ $\mathrm{g} / \mathrm{l}$ at $2.0 \mathrm{~g} / \mathrm{l} \mathrm{KH}_{2} \mathrm{PO}_{4}$ while the maximum production with glucose medium was $58.9 \mathrm{~g} / 1$ at $0.5 \mathrm{~g} / 1 \mathrm{KH}_{2} \mathrm{PO}_{4}$. Shakibaie et al. ${ }^{36}$ indicated that the measured $p$-value of phosphorus in their study was less than 0.05 and concluded that this factor was considerably affected the kojic acid production. The phosphorus element is an important cellular cation for numerous enzymatic reactions. The high concentration of phosphorus might be towards the microbial cell to form phosphate interacted compounds rather than kojic acid especially with glucose as carbon source ${ }^{37}$.

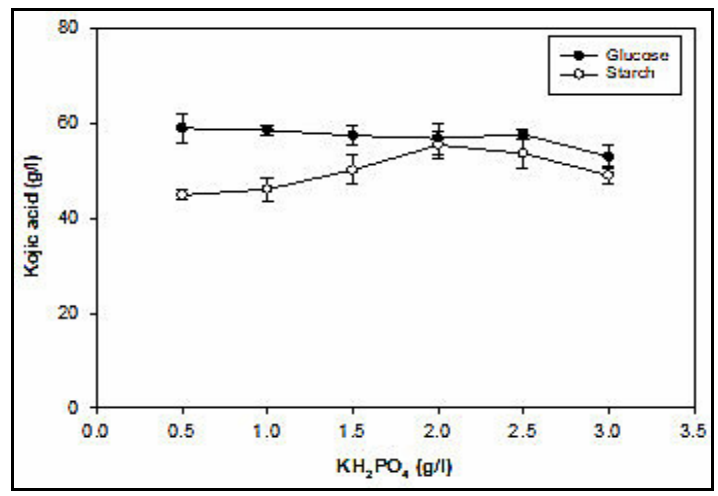

Fig. 1: Kojic acid production by A. oryzae 1034 at different $\mathrm{KH}_{2} \mathrm{PO}_{4}$ concentrations in the fermentation medium $28 \pm 2^{\circ} \mathrm{C}$ for 8 days.
Incubation temperature effect on kojic acid production

Kojic acid yield by A. oryzae 1034 from starch and glucose was affected by varying the incubation temperature. This isolate was able to grow well and produce considerable kojic acid amount the range from $20^{\circ} \mathrm{C}$ to $30^{\circ} \mathrm{C}$ (Fig. 2). The optimum temperature for kojic acid yield during the culture incubation was $28^{\circ} \mathrm{C}$ for both glucose and starch media giving 68.08 and $65.54 \mathrm{~g} / 1$ kojic acid, respectively. The optimum temperature for formation of kojic acid by different fungal species was in the range $25-30^{\circ} \mathrm{C}$ in different studies ${ }^{30,32,34 \& 38}$.

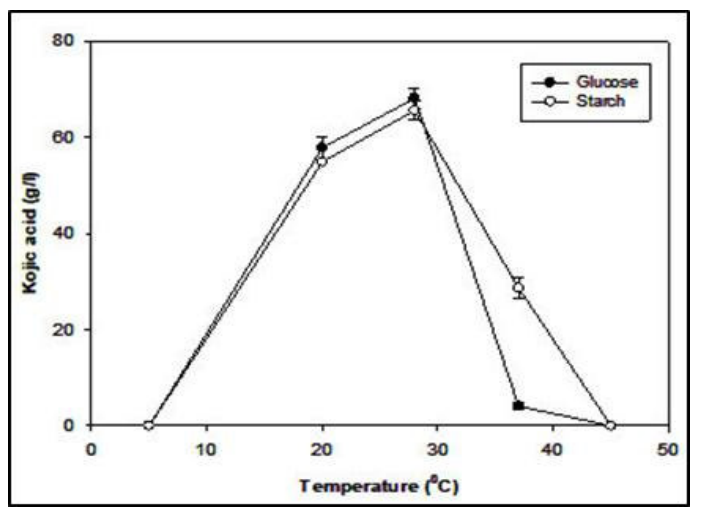

Fig. 2: Kojic acid production by A. oryzae 1034 at different incubation temperatures $\left({ }^{\circ} \mathrm{C}\right)$ for 8 days.

\section{Effect of pH on kojic acid production}

Kojic acid production by A. oryzae 1034 was studied at different initial $\mathrm{pH}$ value and the obtained results were presented in figure 3 . The maximum production $(70.89 \mathrm{~g} / \mathrm{l})$ was obtained in glucose medium at 4.5 while the maximum production $(64.71 \mathrm{~g} / \mathrm{l})$ in starch medium was obtained at 5.0. Kojic acid yield was declined above $\mathrm{pH} 4.5$ and 5.0 for glucose and starch media, respectively. Most of the previous studies that were carried out to determine the optimum $\mathrm{pH}$ for the culture growth and kojic acid biosynthesis were based on the initial medium $\mathrm{pH}^{39 \& 40}$. The highest yield of kojic acid was achieved at acidic medium with $\mathrm{pH}$ ranged from 4 to 6 in similar to the previous studies $^{12 \& 41}$. Rasmey and Basha ${ }^{3}$ informed that enzymes as proteins contain ionizable groups thus their structure and function can be affected by the initial $\mathrm{pH}$ of the medium. Determination 
of the optimal $\mathrm{pH}$ for culture growth and kojic acid biosynthesis is very important since it affects on production of enzymes responsible on kojic acid pathway ${ }^{37}$. Alkaline $\mathrm{pH}$ may lead to the inactivation of enzymes responsible for kojic acid biosynthesis.

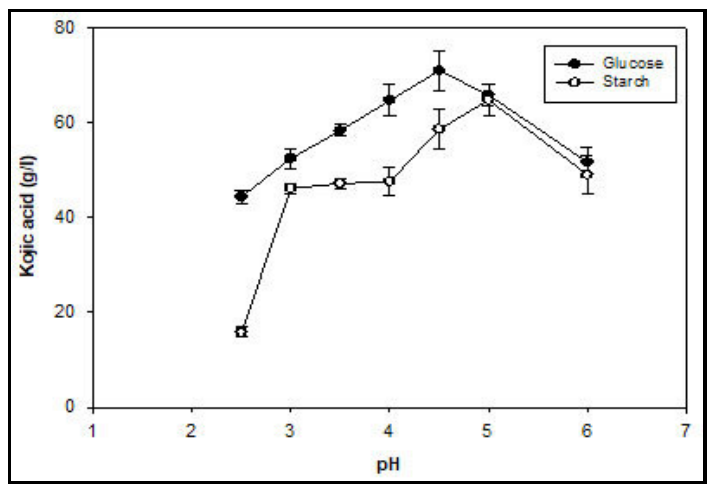

Fig. 3: Kojic acid production by A. oryzae 1034 at different initial $\mathrm{pH}$ values of the fermentation medium at $28^{\circ} \mathrm{C}$ for 8 days.

\section{Incubation period effect on kojic acid production}

Influence of incubation period on kojic acid yield from starch and glucose by $A$. oryzae 1034 was considered in the current investigation (Fig. 4). The presented data shows that the formed kojic acid increases by the gradual increasing of incubation period till reached the maximum production (69.9 and $68.78 \mathrm{~g} / \mathrm{l}$ for glucose and starch, respectively) at 11 days. The obtained results are in consistent with the previous results obtained by different investigations ${ }^{3,9,28,34 \& 37}$. The decrease in kojic acid production after the optimum incubation time might be due to the kojic acid degradation or conversion into other organic compounds $^{3 \& 13}$.

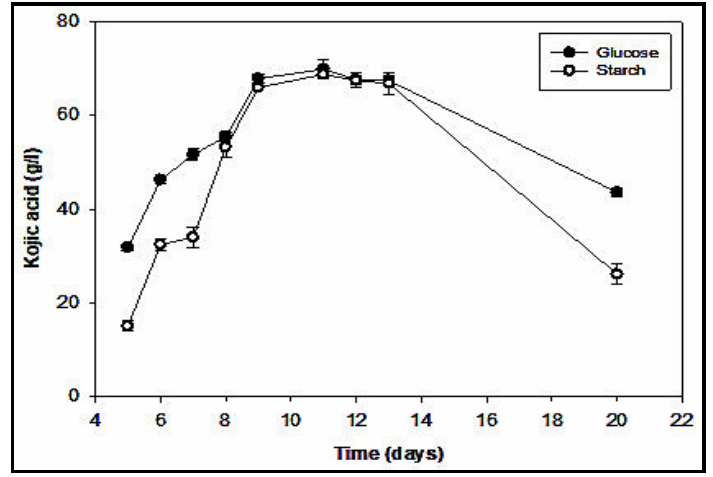

Fig. 4: Kojic acid production by A. oryzae 1034 at different incubation periods (days) at $28^{\circ} \mathrm{C}$.

\section{Effect of substrate concentration on kojic acid production}

The results obtained from studying the effect of substrate (starch and glucose) concentration on kojic acid yield are shown in figure 5. Kojic acid amount was gradually increased by increasing the concentration of the two substrates under investigation. The maximum production was obtained at $60 \mathrm{~g} / \mathrm{l}$ glucose. While, the maximum production in case of starch was obtained at $80 \mathrm{~g} / 1 \mathrm{starch}$. It was revealed that the high concentrations of carbon in the fermentation medium may result in increasing of residual sugar due to the inability of the used microbe to convert the all amounts of sugar into the desired product, based on the osmosis phenomenon ${ }^{9,17 \& 42}$. Above a critical concentration of the tested sugar, water activity decreasing in combine with cells plasmolysis occur causing a decrease in the fermentation rate ${ }^{16 \& 43}$.

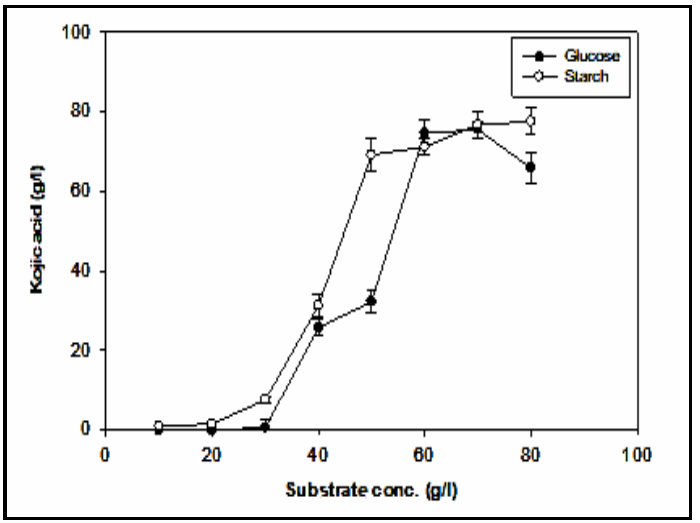

Fig. 5: Kojic acid production by A. oryzae 1034 at different substrate (glucose and starch) concentrations in the fermentation medium at $28^{\circ} \mathrm{C}$ for 11 days.

\section{Effect of amino acid in the medium on kojic acid production}

In the present study, the effect of five amino acids (arginine, histidine, methionine, lysine and alanine) on kojic acid production from glucose and starch was studied (Fig. 6). It is obvious that the kojic acid biosynthesis was decreased by addition of amino acids in the fermentation medium. The decrease of kojic acid might be that amino acids catalyzed other enzymes involved in formation of metabolites rather than kojic acid. Also, amino acids may activate the anabolism of other metabolites needed for fungal growth and adaptation not for production of secondary metabolites ${ }^{44}$. 


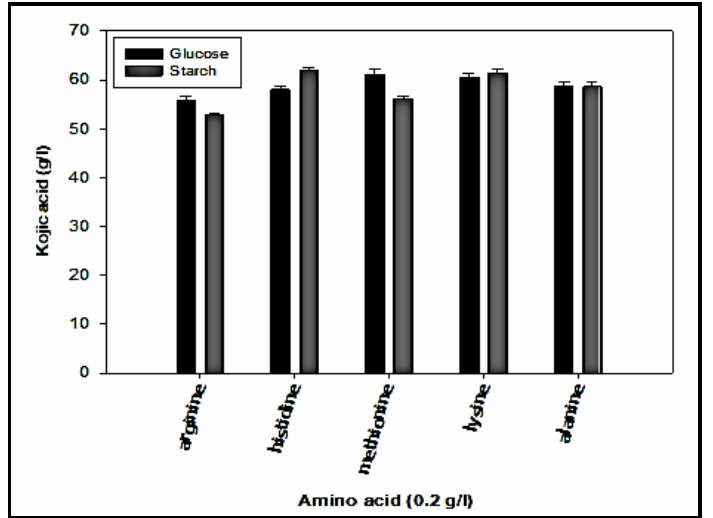

Fig. 6: Kojic acid production by A. oryzae 1034 in the fermentation medium supplemented with different amino acids individually at $28^{\circ} \mathrm{C}$ for 11 days.

Effect of heavy metals in the medium on kojic acid production

The effect of heavy metals (copper hydroxide, lead nitrate, zinc chloride, nickel chloride and manganese chloride) on kojic acid production from glucose and starch was also investigated (Fig. 7). Kojic acid production from glucose was stimulated by addition of heavy metals as trace elements in the fermentation medium. Kojic acid production was increased to $79.3 \mathrm{~g} / \mathrm{l}$ by addition of lead nitrate in glucose medium while the maximum production of kojic acid $(68.83 \mathrm{~g} / \mathrm{l})$ was obtained by addition of zinc chloride in starch medium. $\mathrm{Pb}^{2+}$ and $\mathrm{Zn}^{2+}$ might be strongly activated the enzyme activity responsible for kojic acid biosynthesis ${ }^{45}$. Also, production of an extracellular alpha-amylase enzyme may be activated by the presence of trace elements as cofactors in the fermentation medium.

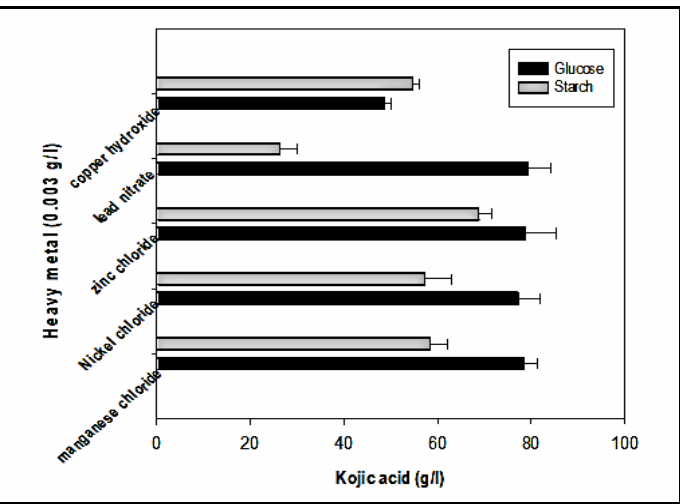

Fig. 7: Kojic acid production by A. oryzae 1034 in the fermentation medium supplemented with different heavy metals individually at $28^{\circ} \mathrm{C}$ for 11 days.

\section{Conclusion}

Kojic acid has much industrial enforcement and its demand is increasing extremely with the growing industries related to its applications. Aspergillus oryzae 1034 is a promising fungal strain for kojic acid production from cheap carbohydrates. Various fermentation mechanisms were applied for kojic acid production from glucose and starch media. Our findings indicated that kojic acid biosynthesis is highly affected by substrate concentration, phosphorus concentrations, amino acids and heavy metals in the fermentation medium. The highest kojic acid concentration (79.3 and $68.8 \mathrm{~g} / \mathrm{l})$ was obtained by incubation the culture at $28 \circ \mathrm{C}$ for 11 days in glucose and starch media with initial $\mathrm{pH} 4.5$ \& 5.0, respectively. This isolate should be subjected to other metabolic and genetic engineering processing to enhance its kojic acid production from different agro-industrial wastes.

\section{REFERENCES}

1. H. A. M. Ammar, S. M. Ezzat and A. M. Houseny, "Improved production of kojic acid by mutagenesis of Aspergillus flavus HAk1 and Aspergillus oryzae HAk2 and their potential antioxidant activity", 3 Biotech., 7 (5), 276 (2017).

2. M. M. Hazzaa, A.M. Saad, H. M. Hassan and E. Ibrahim, "High Production of Kojic acid crystals by isolated Aspergillus oryzae var. effuses NRC14", J. Appl. Sci. Res., 9 (3), 1714-1723 (2013).

3. A. M. Rasmey and A. H. Basha, "Isolation and screening of kojic acid producing isolate of Aspergillus oryzae potentially applicable for production from sugarcane molasses", Int. J. Biol. Res., 4 (2), 119128 (2016).

4. W. Feng, J. Liang, B. Wang, et al., "Improvement of kojic acid production in Aspergillus oryzae AR-47 mutant strain by combined mutagenesis", Bioprocess Biosyst. Eng., 42, 753-761 (2019).

5. R. M. Shehata and S. M. Sabry, "Biotechnological production of kojic acid synthesized by endophytic fungi, Aspergillus oryzae isolated from Euphorbia peplis", Egypt. Acad. J. Biol. Sci. G Microbiol., 12 (2), 35-47 (2020). 
6. A.B. Ariff, M.S. Salleh, B. Ghani, M. A Hassan, G. Rusul, and M. I. A. Karim, "Aeration and yeast extract requirements for kojic acid production by Aspergillus flavus Link", Enzyme Microb. Technol., 19, 545-550 (1996).

7. K. Takamizawa, S. Nakashima, Y. Yahashi, B. K. Kubata, T. Suzuki, K. Kawai, and H. Horitsu, "Optimization of kojic acid production rate using the BoxWilson method", J. Ferment. Bioeng., 82, 414-416 (1996).

8. H. Suryadi, and D. K. P. Sukarna, "Kojic acid production using mixed cultures of Aspergillus Oryzae and Aspergillus Tamarii", Int. J. App. Pharm., 10, 279284 (2018).

9. S. A. El-Aasar, "Cultural conditions studies on kojic acid production by Aspergillus parasiticus", Int. J. Agri. Biol., 8, 468-473 (2006).

10. M. Rosfarizan, M. S. Mohamed, S. Nurashikin, M. M. Saleh and A. B. Ariff, "Kojic acid: Applications and development of fermentation for production", Biotechnol. Mol. Biol. Rev., 5 (2), 24-37 (2010).

11. Y. Ohyama and Y. Mishima, "Melanogenesis-inhibitory effect of kojic acid and its action mechanism", Fragrance J., 6, 53-58 (1990).

12. H. M. Hassan, A. M. Saad, M. M. Hazzaa, and E. I. Ibrahim, "Optimization study for the production of kojic acid crystals by Aspergillus oryzae var. effusus NRC 14 isolate", Int. J. Curr. Microbiol. App. Sci., 3 (10), 133-142 (2014).

13. A. Promsang, V. Rungsardthong, B. Thumthanaruk, C. Puttanlek, D. Uttapap, T. Foophow, V. Phalathanaporn and S. Vatanyoopaisarn, "Effect of culture conditions and medium compositions on kojic acid production by Aspergillus oryzae ATCC 10124", Earth Environ. Sci., 346, 012047 (2019).

14. W. Crueger and A. Crueger, "A textbook of industrial microbiology", Sci. Tech. and Sinauer Associates Inc, London (1984).

15. B. J. Wilson, "Miscellaneous Aspergillus toxins", In Ciegler A (Ed.) Microbes
Toxins, Fungal Toxins VI, Academic Press, New York (1971).

16. A. H. M. Rasmey, H. H. Hassan, O. A. Abdulwahid and A. A. Aboseidah, "Enhancing bioethanol production from sugarcane molasses by Saccharomyces cerevisiae Y17", Egypt. J. Bot., 58 (3), 547-561 (2018).

17. H. Hawary, A. H. M. Rasmey, A. A. Aboseidah, E. S. El-Morsi and M. Hafez, "Enhancement of glycerol production by UV-mutagenesis of the marine yeast Wickerhamomyces anomalus HH16: Kinetics and optimization of the fermentation process", 3 Biotech., 9 (12), 446 (2019).

18. C. M. Christensen, "Influence of small differences in moisture content upon the invasion of harded winter wheat by Aspergillus restrictus and A. repens", Cereal Chem., 40, 385-390 (1963).

19. A. H. Moubasher, "Soil fungi in Qatar and Arab countries", The Scientific and Applied Research Centre, University of Qatar, Doha, Qatar, 566 (1993).

20. R. Bentley, "Preparation and analysis of Kojic acid", Meth. Enzymol., 3, 238-241 (1957).

21. H. M. Soliman, "Mycoflora and Mycotoxins of Cereal Grains in Delta, Egypt", Mycobiolo., 31 (4), 183-190 (2003).

22. A. M. Rasmey, "Biotransformations of steroids by some local fungi belonging to order Mucorales isolated from the New Valley area, Egypt", M. Sc. Thesis, Faculty of Science, Assiut University, Egypt (2009).

23. K. R. N. Reddy, C. S. Reddy and K. Muralidharan, "Detection of Aspergillus spp. and aflatoxin B1 in rice in India", Food Microbiol., 26, 27-31 (2009).

24. S. M. Rustemeyer, W. R. Lamberson, D. R. Ledoux, G. E. Rottinghaus, D. P. Shaw, R. R. Cockrum, K. L. Kessler, K. J. Austin and K. M. Cammack, "Effects of dietary aflatoxin on the health and performance of growing barrows", Anim. Sci. J., 88, 3624-3630 (2010).

25. A. R. El-Shanshoury, S. M. El-Sabbagh, H. A. Emara and H. E. Saba, "Occurrence 
of moulds, toxicogenic capability of Aspergillus flavus and levels of aflatoxins in maize, wheat, rice and peanut from markets in central delta provinces, Egypt", Int. J. Curr. Microbiol. App. Sci., 3 (3), 852-865 (2014).

26. M. A. Klich, "Identification of common Aspergillus species", Centraalbureau voor Schimmelcultures, Netherlands, ISBN-13: 9789070351465, 116 (2002).

27. A. Ogawa, Y. Wakisaka, T. Tanaka, T. Sakiyama and K. Nakanishi, "Production of kojic acid by membrane-surface liquid culture of Aspergillus oryzae NRRL484", J. Ferment. Bioeng., 80, 41-45 (1995).

28. A. B. Ariff, M. Rosfarizan, L. S. Herng, S. Madihah and M. I. A. Karim, "Kinetics and modelling of kojic acid production by Aspergillus flavus link in batch fermentation and resuspended mycelial system", World J. Microbiol. Biotechnol., 13(2), 195-201 (1997).

29. G. A. Burdock, M. G. Soni and G. I. Carabin, "Evaluation of health aspects of kojic acid in food", Regul. Toxicol. Pharmacol., 33, 80-101 (2001).

30. T. Futamura, M. Okabe, T. Tamura, K. Toda, T. Matsunobu and Y. Park, "Improvement of production of kojic acid by a mutant strain Aspergillus oxyzae, MK 107-39", J. Biosci. Bioeng., 91, 272-276 (2001).

31. N. A. Sahasrabudhe and N.V. Sankpal, "Production of organic acids and metabolites on fungi and applications in food industry", In: G.G. Khachatourians and D.K. Arora (Eds.), App. Myc. and Biotech., Agriculture and Food Production, 1, Elsevier; Amsterdam, 387425 (2001).

32. A. S. Gad, "Modification of molasses for kojic acid production by Aspergillus parasiticus", N. Egypt. J. Microbiol., 5, 14-26 (2003).

33. M. Rosfarizan and A. B. Ariff, "Kinetic of kojic acid fermentation by Aspergillus flavus Link S44-1 using sucrose as a carbon source under different $\mathrm{pH}$ conditions", Biotechnol. Bioprocess Eng., 11 (1), $72-79$ (2006).
34. I. A. El-Kady, A. A. Zohri, S. R. and Hamed, "Kojic acid production from agroindustrial by-products using fungi", Biotechnol. Res. Int., 1, 1-10 (2014).

35. M. Y. Kwak and J. S. Rhee, "Controlled mycelial growth for kojic acid production using Ca-alginate-immobilized fungal cells", Appl. Microbiol. Biotechnol., 36, 578-583 (1992).

36. M., Shakibaie, A. Ameri, R. Ghazanfarian, M. Adeli-sardou and $\mathrm{H}$. Forootanfar, "Biotechnology and industrial microbiology statistical optimization of kojic acid production by a UV-induced mutant strain of Aspergillus terreus", Brazilian J. Microbiol., 49 (4), 865-871 (2018).

37. A. Shoaib, A. Bhran, A. H. Rasmey and Y. Mikky, "Optimization of cultural conditions for lipid accumulation by Aspergillus wentii Ras101 and its transesterification to biodiesel: Application of response surface methodology", 3 Biotech., 8 (10), 417 (2018).

38. C. Lin, "The effect of equipping a nonwaven fabrics in the fermenter on the production of kojic acid by Aspergillus flavus", M.Sc Thesis, Chemical Engineering, China (2001).

39. M. T. Lin, J. R. Mahajan, J. C. Dianese and A. Takatsu, "High production of kojic acid crystals by Aspergillus parasiticus UNBF A12 in liquid medium", Appl. Environ. Microbiol., 32, 298-299 (1976).

40. G. Clevstrom and H. Ljunggren, "Aflatoxin formation and the dual phenomenon in Aspergillus flavus Link", Mycopathol., 92, 129-139 (1985).

41. K. B. Durga Devi, P. Vijayalakshmi, V. Shilpa and B. Kumar, "Optimization of cultural parameters for cost effective production of kojic acid by fungal species isolated from soil", Microbiol. Res. J. Int., 7 (5), 255-268 (2015).

42. M. Rosfarizan and A. B. Ariff, "Kinetics of kojic acid fermentation by Aspergillus flavus using different types and concentrations of carbon and nitrogen sources", J. Ind. Microbiol. Biotechnol., 25 (1), 20-24 (2000). 
43. A. H. Rasmey, M. A. Tawfik and M. M. Abdel-Kareem, "Direct transesterification of fatty acids produced by Fusarium solani for biodiesel production: Effect of carbon and nitrogen on lipid accumulation in the fungal biomass", J. Appl. Microbiol., 28 (4), 1074-1085 (2020).

44. J. Miao, M. Wang, L. Ma, T. Li, Q. Huang, D. Liu and Q. Shen, "Effects of amino acids on the lignocellulose degradation by Aspergillus fumigatus Z5: Insights into performance, transcriptional, and proteomic profiles", Biotechnol. Biofuels., 12 (1), 4 (2019).

45. A. H. Rasmey, A. A. Aboseidah and A. K. Youssef, "Application of Langmuir and Freundlich isotherm models onbiosorption of $\mathrm{Pb}^{2+}$ by freez - dried biomass of Pseudomonas aeruginosa", Egypt. J. Microbiol., 53 (1), 37-48 (2018). 


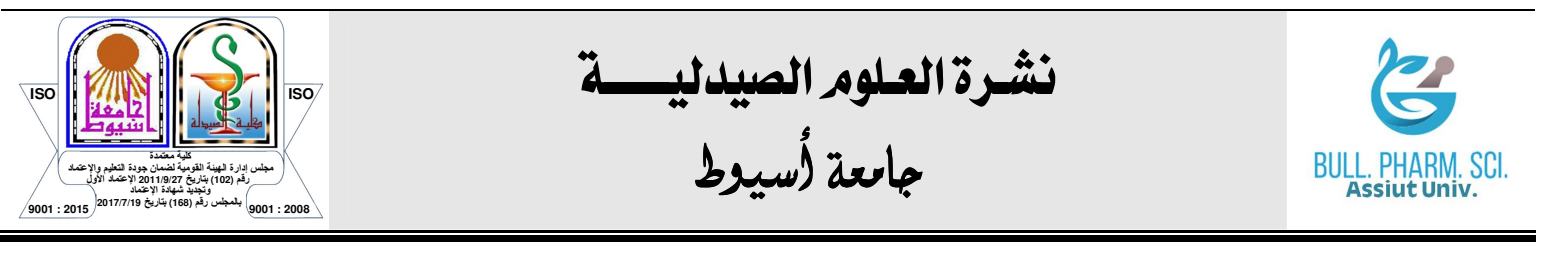

\section{تحسين ظروف الاستزراع لإنتاج حمض الكوجيك في التخمير السطحي بواسطة

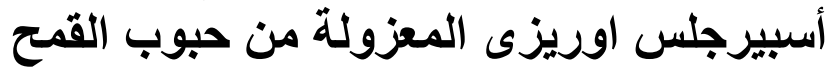

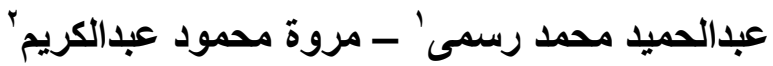 \\ 'قسم النبات والميكروبيولوجى ، كلية العلوم ، جامعة السويس ، السويس ، مصر

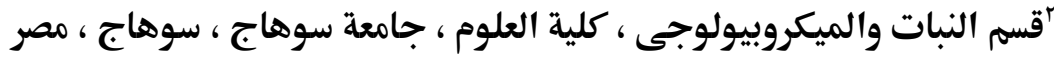

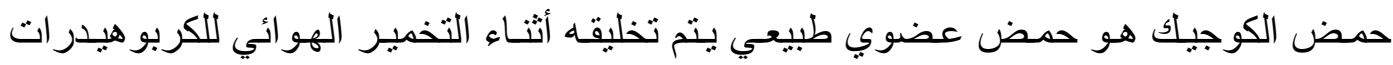

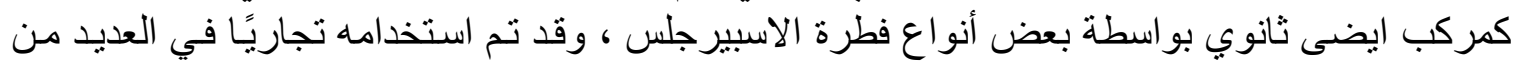

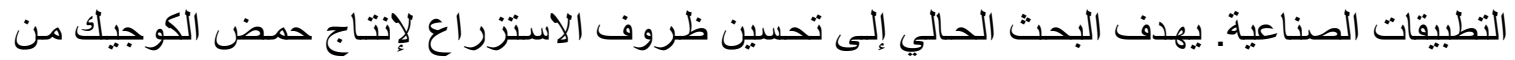

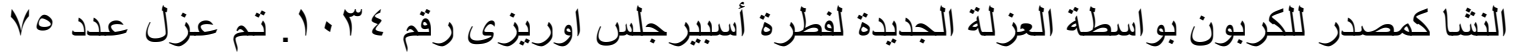

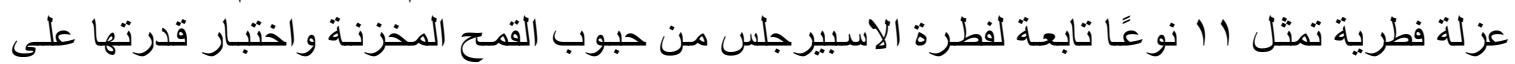

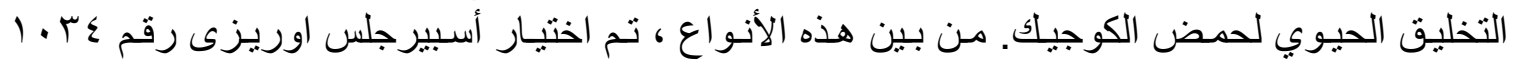

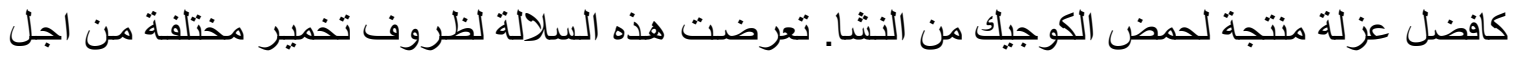

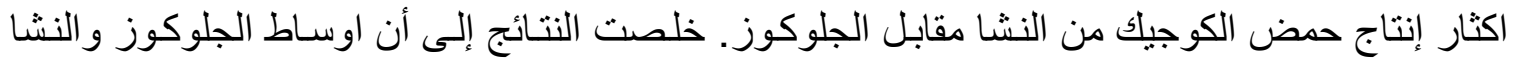

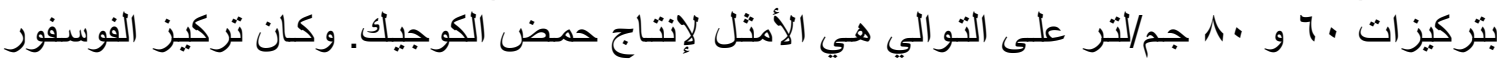

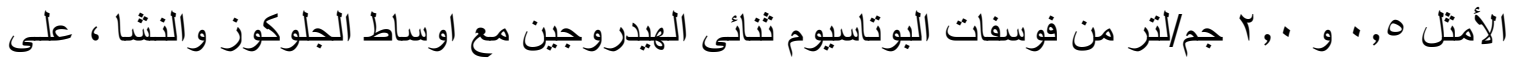

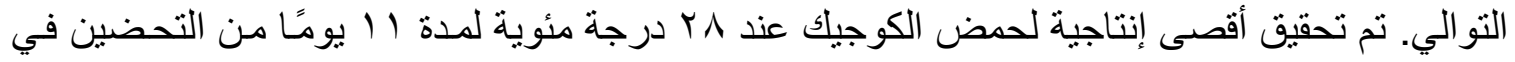

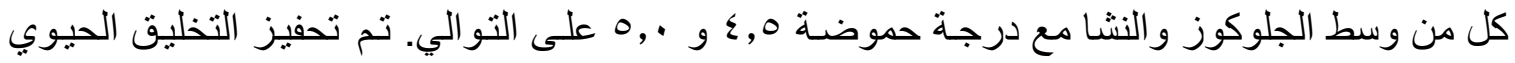

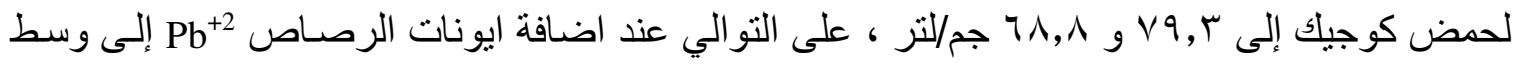

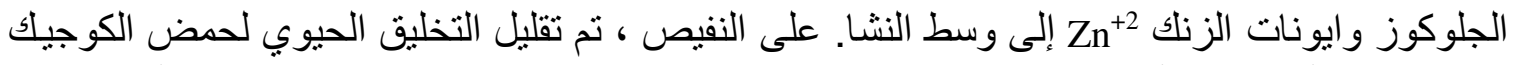

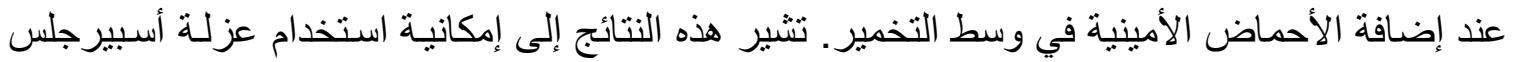

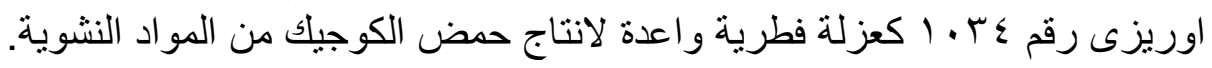

